\title{
Mid-Trimester Cervical Consistency Index and Cervical Length to Predict Spontaneous Preterm Birth in a High-Risk Population
}

\author{
Núria Baños, $\mathrm{MD}^{1}$ Carla Julià, $\mathrm{MD}^{1} \quad$ Núria Lorente, $\mathrm{MD}^{1}$ Silvia Ferrero, MD, $\mathrm{PhD}^{1}$ \\ Teresa Cobo, MD, $\mathrm{PhD}^{1,2}$ Eduard Gratacos, MD, PhD ${ }^{1,2}$ Montse Palacio, MD, $\mathrm{PhD}^{1,2}$
}

\footnotetext{
${ }^{1}$ Fetal i + D Fetal Medicine Research Center, BCNatal - Barcelona Center for Maternal-Fetal and Neonatal Medicine (Hospital Clínic and Hospital Sant Joan de Deu), Institut Clínic de Ginecologia, Obstetricia i Neonatologia, Institut d'Investigacions Biomèdiques August Pi i Sunyer, Universitat de Barcelona, Barcelona, Spain

${ }^{2}$ Centre for Biomedical Research on Rare Diseases (CIBER-ER),

Barcelona, Spain
}

\begin{abstract}
Address for correspondence Núria Baños, MD, PhD, BCNatal - Barcelona Center for Maternal Fetal and Neonatal Medicine Hospital Clínic and Hospital Sant Joan de Déu, Universitat de Barcelona, Fetal i + D Fetal Medicine Research Center, IDIBAPS, Sabino de Arana 1, 08028 Barcelona, Spain (e-mail: nbanos@clinic.cat).
\end{abstract}

Am J Perinatol Rep 2018;8:e43-e50.

\author{
Abstract \\ Keywords \\ - uterine cervix \\ - ultrasound \\ - cervical consistency \\ index \\ - cervical length \\ measurements \\ - spontaneous preterm \\ birth \\ - high-risk population
}

Background Short cervical length $(\mathrm{CL})$ has not been shown to be adequate as a single predictor of spontaneous preterm birth (sPTB) in high-risk pregnancies.

Objective The objective of this study was to evaluate the performance of the midtrimester cervical consistency index $(\mathrm{CCl})$ to predict SPTB in a cohort of high-risk pregnancies and to compare the results with those obtained with the CL.

Study Design Prospective cohort study including high-risk singleton pregnancies between $19^{+0}$ and $24^{+6}$ weeks. The ratio between the anteroposterior diameter of the uterine cervix at maximum compression and at rest was calculated offline to obtain the CCI. Results Eighty-two high sPTB risk women were included. CCI (\%) was significantly reduced in women who delivered $<37^{+0}$ weeks compared with those who delivered at term, while $\mathrm{CL}$ was not. The area under the curve (AUC) of the $\mathrm{CCI}$ to predict SPTB $<37^{+0}$ weeks was 0.73 (95\% confidence interval $[\mathrm{Cl}], 0.61-0.85$ ), being $0.51(95 \% \mathrm{Cl}$, $0.35-0.67), p=0.03$ for $\mathrm{CL}$. The AUC of the CCI to predict sPTB $<34^{+0}$ weeks was 0.68 (95\% Cl, 0.54-0.82), being 0.49 (95\% Cl, 0.29-0.69), $p=0.06$ for CL.

Conclusion $\mathrm{CCl}$ performed better than sonographic $\mathrm{CL}$ to predict SPTB. Due to the limited predictive capacity of these two measurements, other tools are still needed to better identify women at increased risk.

Risk factors of spontaneous preterm birth (sPTB) such as a history of $\mathrm{sPTB}<34^{+0}$ weeks or late miscarriage $\geq 16$ weeks $^{1,2}$ and Müllerian malformations ${ }^{3,4}$ or cervical surgery $^{5}$ have shown limited utility as predictors of sPTB. ${ }^{6-9}$ Neither had short cervical length $(\mathrm{CL})$ shown to be adequate as a single predictor of SPTB in pregnancies with the abovementioned risk factors. ${ }^{10}$ On one hand, the addition of $\mathrm{CL}$ surveillance in pregnancies with a history of SPTB does not

received

April 30, 2017

accepted after revision

December 9, 2017
DOI https://doi.org/

10.1055/s-0038-1636993. ISSN 2157-6998. select all the women who will benefit from treatment. ${ }^{10}$ On the other hand, although CL seems to be shorter in women who have undergone cervical surgery or with Müllerian malformations, $4,11,12$ it has not been demonstrated to be an independent risk factor for SPTB. ${ }^{13}$ Therefore, the use of other or the combination of SPTB prediction tools together with sonographic $\mathrm{CL}$ is needed to improve the identification of women at risk who will benefit from the treatments
Copyright $@ 2018$ by Thieme Medical Publishers, Inc., 333 Seventh Avenue, New York, NY 10001, USA. Tel: +1(212) 584-4662.
License terms

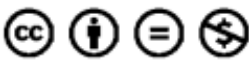


currently available. ${ }^{14-17}$ In this study, we evaluate the cervical consistency index (CCI), an ultrasound measurement that aims to estimate cervical softness by measuring the anteroposterior diameter of the uterine cervix before (AP) and at maximal compression $\left(\mathrm{AP}^{\prime}\right)$ with the vaginal ultrasound probe and calculating the ratio between the two measurements $\left(\mathrm{AP}^{\prime} / \mathrm{AP} \times 100\right){ }^{18}$ The lower the $\mathrm{CCI}$, the higher the cervical compressibility and cervical softness. Studies based on animal models assessing cervical remodeling along pregnancy suggest an initial phase of cervical softening which starts soon after conception and occurs progressively along pregnancy, followed by a shortening and ripening phase closer to delivery. In addition, slight changes in CL have been associated with increased cervical softening and cervical volume without substantial effacement before term. ${ }^{19-23}$ Therefore, assessment of the early stage in cervical remodeling such as softening using the CCI would potentially allow early identification of the women at increased risk. In fact, in a previous publication, $\mathrm{CCI}$ was found to be a better predictor of $\mathrm{sPTB}<37^{+0}$ and $<34^{+0}$ weeks than sonographic $\mathrm{CL}^{24}$ during the second-trimester scan in a low-risk population.

The aim of this study was to evaluate the performance of mid-trimester CCI to predict SPTB in a cohort of high-risk pregnancies and compare the results with those obtained with mid-trimester sonographic CL.

\section{Materials and Methods}

\section{Study Population}

This was a prospective cohort study including singleton pregnancies between $19^{+0}$ and $24^{+6}$ weeks of gestational age attending the preterm birth prevention clinic (PBPC) from BCNatal, Barcelona. Women were included if they presented at least, one of the following SPTB risk factors: (1) history of sPTB $<34^{+0}$ weeks or late miscarriage $>16$ weeks, (2) Müllerian malformation or cervical conization, (3) $\mathrm{CL}<25 \mathrm{~mm}$ or previable premature prelabor rupture of membranes (PPROMs) if detected before the routine second-trimester ultrasound. SPTB was defined as a birth $<37^{+0}$ weeks' related to the spontaneous onset of labor with intact membranes or with PPROMs. PTB for fetal or maternal indications including induction of labor (IOL) for PPROM was excluded from the study.

In our center, high SPTB risk patients are followed in the PBPC every 2 to 3 weeks from week 14 depending on the risk factor and clinical findings. Progesterone is indicated in women with a history of SPTB, late miscarriage, Müllerian malformation, or cervical conization with a $\mathrm{CL}<25 \mathrm{~mm}$ and in all women with a $\mathrm{CL}<20 \mathrm{~mm}$. Prophylactic cerclage is performed in women with $\geq 3 \mathrm{sPTB}$ or late miscarriages and in women with $\geq 1$ previous SPTB or late miscarriage after conization. Prophylactic cerclage is also indicated with $\geq 2$ SPTB or late miscarriages if they are well documented in the medical records. Ultrasound-indicated cervical cerclage is indicated at up to 24 weeks in women with a history of $\geq 1$ sPTB or late miscarriage with progressive cervical shortening $<25 \mathrm{~mm}$ despite progesterone treatment. Physical examination-indicated cervical cerclage is indicated in women at up to 24 weeks when there is membrane exposure, after pre- viously ruling out intra-amniotic infection by amniocentesis. Cervical pessary is not yet implemented in our routine clinical practice while awaiting further evidence of its possible benefits.

Information on baseline demographic characteristics and obstetric history were prospectively collected from paper forms filled in by the pregnant women. Perinatal outcomes were retrieved from hospital files. The primary outcome was to compare the diagnostic accuracy of $\mathrm{CCI}$ and $\mathrm{CL}$ to predict sPTB $<37^{+0}$ weeks. The secondary outcomes were to compare the diagnostic accuracy of $\mathrm{CCI}$ and $\mathrm{CL}$ to predict SPTB $<34^{+0}$ weeks.

\section{Image Acquisition and Cervical Measurements}

Image acquisition was performed with a Siemens Sonoline Antares (Siemens Medical Systems, Malvern, PA) and a Voluson 780 Pro, S6, E6 and E8 (GE Medical Systems, Milwaukee, $\mathrm{WI}$ ) with a vaginal probe with a frequency between 2 and $10 \mathrm{MHz}$. Images were acquired in lithotomy position by three trained gynecologists running the PBPC in our center. An image acquisition guide and quality criterion were defined to ensure the optimal acquisition parameters and explained in depth in a previous publication. ${ }^{24}$ Briefly, to acquire the basal image, a sagittal view of the cervix was obtained without exerting any pressure with the transducer, identifying the internal and external os as well as the cervical canal (-Fig. 1a). To acquire the image at maximal compression, pressure was applied softly and progressively on the cervix until no further compression of the anteroposterior diameter could be observed as described by Parra-Saavedra et $\mathrm{al}^{18}$ (-Fig. 1b). The images were digitally collected in the original Digital Imaging and Communication in Medicine format, downloaded from the medical imaging software and stored in a research imaging server for the offline analysis. A custom-made program with a graphical user interface (GUI) using MATLAB R2010b (version 7.11.0.584; MATLAB; The Mathworks Inc., Natick, MA) was designed for this purpose also following the procedure described by Parra-Saavedra et al. ${ }^{18}$ Quality criteria to consider an image for CCI and CL measurements were (1) visualization of the entire cervix and (2) the cervical canal in the basal image is not inclined more than 45 degrees over the horizontal plane as estimated subjectively or-in doubtful cases-using the angle tool of the GUI. CCI was semiautomatically calculated as the ratio between the anteroposterior diameter of the uterine cervix at maximal compression $\left(\mathrm{AP}^{\prime}\right)$ and the diameter in the basal image (AP): $\mathrm{CCI}=\mathrm{AP}^{\prime} / \mathrm{AP} \times 100$ (-Fig. 1). $\mathrm{CCI}$ and $\mathrm{CL}$ measurements were performed offline in a personal computer by N.B. and blinded to the managing physicians and patients.

\section{Statistical Analysis}

Data distribution was assessed according to the Shapiro-Wilk's test of normality. Results were described as absolute and relative frequencies for qualitative variables and median and interquartile range for quantitative variables. Continuous data were compared with Student's $t$-test or analysis of variance and with Mann-Whitney's $U$-test or Kruskal-Wallis' test for 


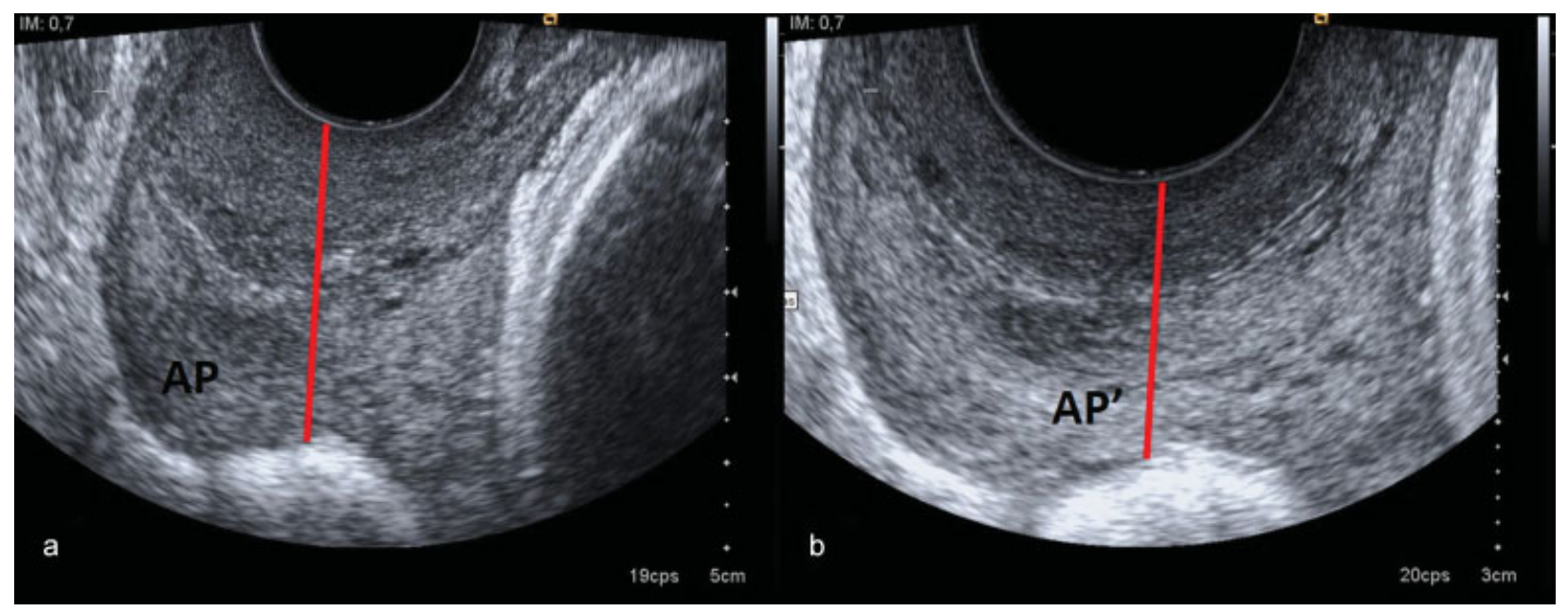

Fig. 1 Image of the uterine cervix in the same patient before (a) and at maximal compression (b) with the vaginal probe and the calculation of the cervical consistency index $(\mathrm{CCI}): \mathrm{AP}^{\prime} / \mathrm{AP} \times 100$.

normally and nonnormally distributed data, respectively. Categorical variables were compared with the chi-square or Fisher's exact test. A multivariate logistic regression model was performed to assess if $\mathrm{CCl}$ and $\mathrm{CL}$ were independently associated with SPTB and to adjust for candidate confounders. If the potential confounder changed the estimate of the risk by $10 \%$ or more, it was considered importantly different and was left in the model. Receiver operating characteristic (ROC) curves for $\mathrm{CCl}$ and $\mathrm{CL}$ and for a logistic regression model including $\mathrm{CCI}$ and $\mathrm{CL}$ as predictive variables (both variables forced into the model) were obtained to determine the area under the curve (AUC) for the prediction of sPTB $<37^{+0}$ and $<34^{+0}$ weeks. The resulting AUCs were compared using the DeLong's method. The sensitivity, specificity, negative predictive value (NPV), positive predictive value (PPV), and positive and negative likelihood ratios ( $\mathrm{LR}+$ and $\mathrm{LR}-$ ) with their 95\% confidence intervals (CIs) in predicting $\mathrm{SPTB}<37^{+0}$ and $<34^{+0}$ weeks were calculated for the optimal cutoff based on the ROC curve and for different cutoff points for $\mathrm{CCI}$ and $\mathrm{CL}$ and for the combined use of $\mathrm{CCI}$ and $\mathrm{CL}$ (i.e., either or both below the optimal cutoff). The optimal cutoff is that corresponding to the point on the ROC curve situated farthest from the reference line. The McNemar's test was used to compare the diagnostic accuracy of $\mathrm{CCl}$ and $\mathrm{CL}$ at certain cutoff points. The relationship between $\mathrm{CCI}$ and $\mathrm{CL}$ and risk of PTB was analyzed using logistic regression and the estimated probability of PTB by CCI and CL was calculated. A two-sided type I error of $5 \%$ was applied in the statistical tests. All the analyses were performed using STATA/IC 13.0 (StataCorp; 4905 Lakeway Drive, College Station, TX).

\section{Results}

From November 2014 to November 2015, a total of 96 women at high risk of SPTB were eligible for inclusion. Six women with PPROM were excluded (four because they presented a previable PPROM and subsequently underwent a termination of pregnancy and two women because of a PPROM which required an IOL at $34^{+0}$ weeks according to the hospital protocol). In addition, eight women were excluded because the images did not fulfill the quality criteria. Finally, 82 high sPTB risk women were included in the analysis. Demographic and pregnancy characteristics of women who delivered $<37^{+0}$ weeks and those who delivered at term are shown in - Table 1. The rate of sPTB $<37^{+0}$ weeks was $26.8 \%$, being $17.1 \%$ at $<34^{+0}$ weeks. Regarding the demographic characteristics between the SPTB and the term groups, women who delivered preterm were older and the gestational age at scan was significantly greater. A history of preterm delivery was overrepresented in the term group compared with the SPTB group, being $66.7 \%(40 / 60)$ versus $31.8 \%(7 / 22)$, respectively. Of the nine women with a history of SPTB and a $\mathrm{CL}<25 \mathrm{~mm}$, only three delivered preterm. Of the 17 women with a uterine factor, 4 out of 12 with a Müllerian malformation delivered preterm. The five women with a prior conization delivered at term. The median gestational age of the previous SPTB or late miscarriage was $25^{+0}$ weeks and did not differ between the groups. Regarding sonographic measurements, the median CL (mm) at mid-pregnancy was not significantly different between the SPTB and the term groups or with the proportion of short CL ( $\mathrm{CL} \leq 20$ or $<25 \mathrm{~mm}$ ). On the contrary, the $\mathrm{CCI}$ (\%) was significantly reduced in the women with a preterm delivery compared with the term group. Multivariate logistic regression analysis showed that only $\mathrm{CCI}$ was independently associated with SPTB when adjusted for confounders (history of SPTB and cerclage): CCI-adjusted odds ratio of 0.93 (95\% CI, 0.88-0.98; $p=0.02$ ). CL was not associated with SPTB.

The AUC of the CCI to predict SPTB $<37^{+0}$ weeks was 0.73 (95\% CI, 0.61-0.85), while the AUC of CL was 0.51 (95\% CI, 0.35$0.67)(p=0.03)(-$ Fig. 2). The optimal CCI and CL cutoff points to predict sPTB $<37^{+0}$ weeks were $59.4 \%$ (sensitivity $72.7 \%$, specificity $63.3 \%$ ) and $34.0 \mathrm{~mm}$ (sensitivity $54.5 \%$, specificity $56.7 \%$ ) as shown in - Table 2 . The discriminative performances of the different CCI and CL cutoffs and of the combined use of CL and $\mathrm{CCI}$ (both or either being below the optimal cutoff) are also shown in - Table 2. A CL $<25 \mathrm{~mm}$, which is the cutoff currently used in clinical practice had a sensitivity of $31.8 \%$, a specificity 
Table 1 Demographic and pregnancy characteristics of the SPTB $<37^{+0}$ weeks and term groups

\begin{tabular}{|c|c|c|c|c|}
\hline & Total, $n=82$ & Term birth, $n=60$ & sPTB $<37 w k, n=22$ & $p$-Value ${ }^{\mathrm{a}}$ \\
\hline Maternal age & $34(31-37)$ & $33(30-36)$ & $36(32-39)$ & 0.03 \\
\hline BMI & $22.7(21.0-27.0)$ & $22.6(21.2-27.2)$ & $23.4(20.4-25.9)$ & 0.57 \\
\hline Caucasian ethnicity & $62(75.6)$ & $47(78.3)$ & $15(68.2)$ & 0.34 \\
\hline Smoking & $18(22.0)$ & $12(20)$ & $4(18.2)$ & 0.85 \\
\hline Nulliparous & $13(17.6)$ & $11(18.3)$ & $7(31.8)$ & 0.19 \\
\hline \multicolumn{5}{|l|}{ PTB risk } \\
\hline History sPTB & $47(57.3)$ & $40(66.7)$ & $7(31.8)$ & 0.005 \\
\hline Uterine factor & $17(20.7)$ & $13(21.7)$ & $4(18.2)$ & 0.73 \\
\hline PPROM & $7(8.5)$ & $0(0)$ & $7(31.8)$ & $<0.001$ \\
\hline Short CL & $11(13.4)$ & $7(11.7)$ & $4(18.2)$ & 0.44 \\
\hline GA prior sPTB & $25(22-31)$ & $25(21.5-31.5)$ & $25(22-31)$ & 0.85 \\
\hline GA at scan $(w k+d)$ & $21.3(20.5-23.1)$ & $21.1(20.4-22.5)$ & $22.1(21-23.5)$ & 0.03 \\
\hline Progesterone & $12(14.6)$ & $10(16.7)$ & $2(9.1)$ & 0.39 \\
\hline GA start progesterone $(w k+d)$ & $20.5(20-22.6)$ & $20.6(20-22.6)$ & $20(16-24)$ & 0.50 \\
\hline Cerclage & $15(18.3)$ & $7(11.7)$ & $8(36.4)$ & 0.01 \\
\hline GA start cerclage $(w k+d)$ & $20(15-22)$ & $16.5(14-20)$ & $21.5(19-22)$ & 0.16 \\
\hline sPTB $<37$ & $22(26.8)$ & - & - & NA \\
\hline sPTB $<34$ & $14(17.1)$ & - & - & NA \\
\hline $\mathrm{CL}$ at $\operatorname{scan}(\mathrm{mm})$ & $34.8(26.1-41.4)$ & $35.2(29.0-40.3)$ & $30.8(24.1-44.1)$ & 0.90 \\
\hline $\mathrm{CL}<25 \mathrm{~mm}(\%)$ & $18(21.6)$ & $11(18.3)$ & $7(31.8)$ & 0.19 \\
\hline $\mathrm{CL} \leq 20 \mathrm{~mm}(\%)$ & $10(12.2)$ & $7(11.7)$ & $3(13.6)$ & 0.81 \\
\hline $\mathrm{CCl}$ at scan $(\%)$ & $60.6(50.4-66.6)$ & $62.2(52.8-70.0)$ & $50.4(44.4-61.7)$ & 0.001 \\
\hline Spontaneous onset of labor & $59(72.0)$ & $37(61.7)$ & $22(100)$ & 0.001 \\
\hline Vaginal delivery & $66(80.5)$ & $50(83.3)$ & $16(72.3)$ & 0.28 \\
\hline GA at delivery $(w k+d)$ & $38.4(35-40.1)$ & $39.1(38.3-40.3)$ & $30.6(26.1-34.3)$ & NA \\
\hline Birth weight (g) & $3,084(2,160-3,440)$ & $3,295(2,990-3,544)$ & $1,624(1,000-2,090)$ & NA \\
\hline
\end{tabular}

Abbreviations: $\mathrm{BMI}$, body mass index; $\mathrm{CCl}$, cervical consistency index; $\mathrm{CL}$, cervical length; $\mathrm{GA}$, gestational age; PPROM, premature prelabor rupture of membrane; PTB, preterm birth; sPTB, spontaneous preterm birth.

Note: Data given as median (interquartile range) or $n(\%)$.

${ }^{\mathrm{a}}$ Comparison between sPTB and term groups.

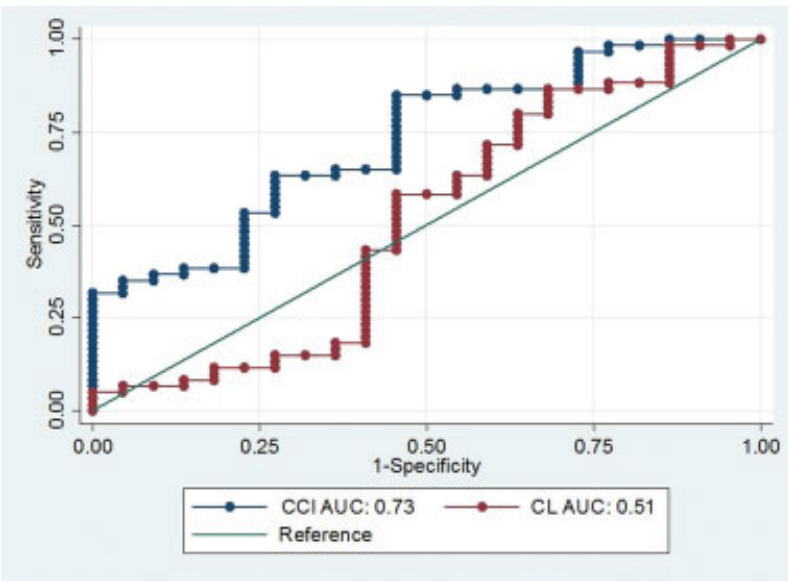

Fig. 2 Receiver operating characteristic (ROC) curves for the cervical consistency index $(\mathrm{CCl})$ and cervical length $(\mathrm{CL})$ with regard to predicting spontaneous preterm birth (sPTB) $<37$ weeks.

Abrevations: AUC; Area Under the Curve. of $81.7 \%$, a PPV of $38.9 \%$, a NPV of $76.6 \%$, and a $L R+$ of 1.74 and LR - of 0.84 . On comparing certain cutoff points to identify sPTB, the McNemar's exact test suggested that there was no statistically significantly difference between optimal cutoff points of CCI and CL ( $p=0.22)$ and between the 10th centiles of CCI and $\mathrm{CL}$ (CCI of $45 \%$ and $\mathrm{CL}<20 \mathrm{~mm})(p=0.38$ ).

The AUC of the CCI to predict SPTB $<34^{+0}$ weeks was 0.68 (95\% CI, 0.54-0.82), while the AUC of CL was 0.49 (95\% CI, 0.29-0.69) ( $p=0.06)$ (-Fig. 3). The optimal cutoff points of the $\mathrm{CCI}$ and $\mathrm{CL}$ to predict SPTB $<34^{+0}$ weeks were $59.4 \%$ (sensitivity 78.6\%, specificity $58.8 \%$ ) and $29.7 \mathrm{~mm}$ (sensitivity $42.9 \%$, specificity $69.1 \%$ ) as shown in -Table 3 . The McNemar's exact test suggested that to identify sPTB $<34$ weeks, there was no statistically significantly difference between optimal cutoffs of CCI and CL $(p=0.22)$ and between the 10 th centiles of $\mathrm{CCI}$ and $\mathrm{CL}$ ( $45 \%$ and $\mathrm{CL}<20$ $\mathrm{mm})(p=0.57)$. The discriminative performance of the different CCI and CL cutoffs and of the combined use of CL 
Table 2 Discriminative performance of the $\mathrm{CCl}$ and $\mathrm{CL}$ measured with ultrasound and with the combination of the two measurements with regard to predicting spontaneous preterm birth $<37^{+0}$ weeks

\begin{tabular}{|c|c|c|c|c|c|c|c|}
\hline & Cutoff $^{\mathrm{a}}$ & $\begin{array}{l}\text { Sensitivity } \\
\text { (95\% CI) }\end{array}$ & $\begin{array}{l}\text { Specificity } \\
(95 \% \mathrm{Cl})\end{array}$ & $\begin{array}{l}\text { PPV } \\
(95 \% \mathrm{Cl})\end{array}$ & $\begin{array}{l}\text { NPV } \\
(95 \% \mathrm{Cl})\end{array}$ & $\begin{array}{l}\mathrm{LR}+ \\
(95 \% \mathrm{Cl})\end{array}$ & $\begin{array}{l}\text { LR- } \\
(95 \% \mathrm{Cl})\end{array}$ \\
\hline \multirow[t]{4}{*}{$\mathrm{CCl}$} & $<45 \%$ & $\begin{array}{l}27.3 \%(13.1-48.2) \\
(6 / 22)\end{array}$ & $\begin{array}{l}95.0 \%(86.3-98.3) \\
(57 / 60)\end{array}$ & $\begin{array}{l}66.7 \%(35.4-87.9) \\
(6 / 9)\end{array}$ & $\begin{array}{l}78.1 \%(67.3-86.0) \\
(57 / 73)\end{array}$ & $\begin{array}{l}5.5 \\
(1.5-19.6)\end{array}$ & $\begin{array}{l}0.8 \\
(0.6-0.9)\end{array}$ \\
\hline & $<50 \%$ & $\begin{array}{l}45.5 \%(26.9-65.3) \\
(10 / 22)\end{array}$ & $\begin{array}{l}86.7 \%(75.8-93.1) \\
(52 / 60)\end{array}$ & $\begin{array}{l}55.6 \%(33.7-75.4) \\
(10 / 18)\end{array}$ & $\begin{array}{l}81.5 \%(70.0-88.9) \\
(52 / 64)\end{array}$ & $\begin{array}{l}3.4 \\
(1.5-7.5)\end{array}$ & $\begin{array}{l}0.6 \\
(0.4-0.9)\end{array}$ \\
\hline & $<55 \%$ & $\begin{array}{l}54.5 \%(34.7-73.1) \\
(12 / 22)\end{array}$ & $\begin{array}{l}70.0 \%(57.5-80.1) \\
(42 / 60)\end{array}$ & $\begin{array}{l}40.0 \%(24.6-57.7) \\
(12 / 30)\end{array}$ & $\begin{array}{l}80.8 \%(68.1-89.2) \\
(42 / 52)\end{array}$ & $\begin{array}{l}1.8 \\
(1.1-3.1)\end{array}$ & $\begin{array}{l}0.6 \\
(0.4-1.1)\end{array}$ \\
\hline & $59.4 \%^{b}$ & $\begin{array}{l}72.7 \%(51.8-81.8) \\
(16 / 22)\end{array}$ & $\begin{array}{l}63.7 \%(49.0-72.9) \\
(37 / 60)\end{array}$ & $\begin{array}{l}41.0 \%(27.1-56.6) \\
(16 / 39)\end{array}$ & $\begin{array}{l}86.0 \%(72.3-93.4) \\
(37 / 43)\end{array}$ & $\begin{array}{l}1.9 \\
(1.3-2.9)\end{array}$ & $\begin{array}{l}0.4 \\
(0.2-0.9) \\
\end{array}$ \\
\hline \multirow[t]{4}{*}{$\mathrm{CL}$} & $\leq 20 \mathrm{~mm}$ & $\begin{array}{l}13.6 \%(4.7-33.3) \\
(3 / 22)\end{array}$ & $\begin{array}{l}88.3 \%(77.8-94.2) \\
(53 / 60)\end{array}$ & $\begin{array}{l}30.0 \%(10.5-60.3) \\
(3 / 10)\end{array}$ & $\begin{array}{l}73.6 \%(62.4-82.4) \\
(53 / 72)\end{array}$ & $\begin{array}{l}1.2 \\
(0.3-4.1)\end{array}$ & $\begin{array}{l}1.0 \\
(0.8-1.2)\end{array}$ \\
\hline & $<25 \mathrm{~mm}$ & $\begin{array}{l}31.8 \%(16.4-52.7) \\
(7 / 22)\end{array}$ & $\begin{array}{l}81.7 \%(70.1-89.4) \\
(49 / 60)\end{array}$ & $\begin{array}{l}38.9 \%(20.3-61.4) \\
(7 / 18)\end{array}$ & $\begin{array}{l}76.6 \%(64.9-85.3) \\
(49 / 64)\end{array}$ & $\begin{array}{l}1.7 \\
(0.8-3.9)\end{array}$ & $\begin{array}{l}0.8 \\
(0.6-1.1)\end{array}$ \\
\hline & $<30 \mathrm{~mm}$ & $\begin{array}{l}40.9 \%(23.3-61.3) \\
(9 / 22)\end{array}$ & $\begin{array}{l}70.0 \%(57.5-80.1) \\
(42 / 60)\end{array}$ & $\begin{array}{l}33.3 \%(18.6-52.2) \\
(9 / 27)\end{array}$ & $\begin{array}{l}76.4 \%(63.7-85.6) \\
(42 / 55)\end{array}$ & $\begin{array}{l}1.4 \\
(0.7-2.6)\end{array}$ & $\begin{array}{l}0.8 \\
(0.6-1.2)\end{array}$ \\
\hline & $34.0 \mathrm{~mm}^{\mathrm{b}}$ & $\begin{array}{l}54.5 \%(34.7-73.1) \\
(12 / 22)\end{array}$ & $\begin{array}{l}56.7 \%(44.1-68.4) \\
(34 / 60)\end{array}$ & $\begin{array}{l}31.6 \%(19.1-47.5) \\
(12 / 38)\end{array}$ & $\begin{array}{l}77.3 \%(63.0-87.2) \\
(34 / 44)\end{array}$ & $\begin{array}{l}1.3 \\
(0.8-2.0) \\
\end{array}$ & $\begin{array}{l}0.8 \\
(0.5-1.3)\end{array}$ \\
\hline $\begin{array}{l}\mathrm{CCl} \text { and } \mathrm{CL} \\
\text { below cutoff }\end{array}$ & $\begin{array}{l}<59.4 \% \text { and } \\
<34.0 \mathrm{~mm}\end{array}$ & $\begin{array}{l}50 \%(30.7-69.3) \\
(11 / 22)\end{array}$ & $\begin{array}{l}73.3 \%(61.0-82.9) \\
(44 / 60)\end{array}$ & $\begin{array}{l}40.7 \%(24.5-59.3) \\
(11 / 27)\end{array}$ & $\begin{array}{l}80.0 \%(67.6-88.4) \\
(44 / 55)\end{array}$ & $\begin{array}{l}1.9 \\
(1.0-3.4)\end{array}$ & $\begin{array}{l}0.7 \\
(0.4-1.1)\end{array}$ \\
\hline $\begin{array}{l}\mathrm{CCl} \text { or } \mathrm{CL} \\
\text { below cutoff }\end{array}$ & $\begin{array}{l}<59.4 \% \text { or } \\
<34.0 \mathrm{~mm}\end{array}$ & $\begin{array}{l}77.3 \%(56.6-89.9) \\
(17 / 229)\end{array}$ & $\begin{array}{l}46.7 \%(34.6-59.1) \\
(28 / 60)\end{array}$ & $\begin{array}{l}34.7 \%(22.9-48.7) \\
(17 / 49)\end{array}$ & $\begin{array}{l}84.8 \%(69.1-93.3) \\
(28 / 33)\end{array}$ & $\begin{array}{l}1.4 \\
(1.1-2.0)\end{array}$ & $\begin{array}{l}0.5 \\
(0.2-1.1)\end{array}$ \\
\hline
\end{tabular}

Abbreviations: $\mathrm{CCl}$, cervical consistency index; $\mathrm{Cl}$, confidence interval; $\mathrm{CL}$, cervical length; $\mathrm{LR}$ - , negative likelihood ratio; $\mathrm{LR}+$, positive likelihood ratio; NPV, negative predictive value; PPV, positive predictive value.

${ }^{\mathrm{a}} \mathrm{Values}$ below the cutoff indicate increased risk.

boptimal cutoff based on the receiver operating characteristic curve.

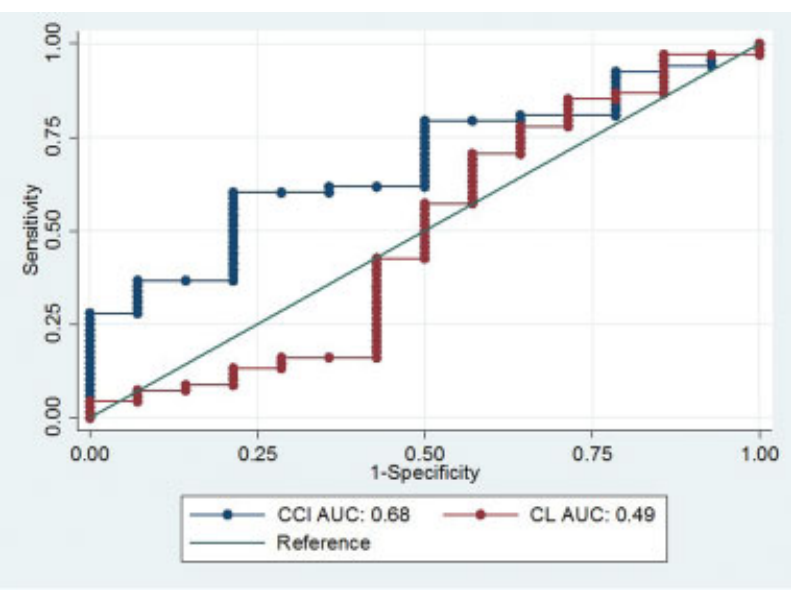

Fig. 3 Receiver operating characteristic (ROC) curves for the cervical consistency index $(\mathrm{CCl})$ and cervical length $(\mathrm{CL})$ with regard to predicting spontaneous preterm birth (sPTB) $<34$ weeks. Abrevations: AUC; Area Under the Curve.

and CCI are also shown in - Table 3. The AUC for a model including both $\mathrm{CCI}$ and $\mathrm{CL}$ (both included to the model) to predict sPTB $<37^{+0}$ weeks was 0.74 (95\% CI, 0.63-0.86), which is not significantly different from the AUC of $\mathrm{CCI}$ alone (0.73); $p=0.57$. The AUC for a model including both $\mathrm{CCI}$ and CL to predict SPTB $<34^{+0}$ weeks was 0.68 (95\% CI, 0.540.82 ), which is the same as that for $\mathrm{CCI}$ alone. The estimated probabilities of sPTB $<37^{+0}$ and $<34^{+0}$ weeks according to the CCI and CL are shown in -Figs. 4 and 5.

\section{Discussion}

The main finding of this study is that in a high SPTB risk population assessed during mid-gestation, CCI performs significantly better than sonographic CL to predict SPTB $<37^{+0}$ and $<34^{+0}$ weeks and is independently associated with SPTB. The combination of CCI with CL does not improve the diagnostic accuracy.

Interestingly, in the high-risk population, the $\mathrm{CCI}$ was significantly reduced in women who had a SPTB $<37^{+0}$ weeks, while CL was not. These findings support the idea that despite use in clinical practice, CL measurement in high-risk singleton pregnancies is not adequate as a stand-alone predictor of SPTB. ${ }^{10}$ It is important to highlight that when compared with a cohort of singleton low SPTB risk pregnancies published in a previous study, ${ }^{24}$ both CCI and CL measurements were significantly reduced in the high-risk compared with the lowrisk pregnancies. However, the diagnostic accuracy of both measurements was better in the low-risk population than in the high-risk population. ${ }^{24}$ This may be due to the fact that up to $32.9 \%$ (27/82) of high sPTB risk women in our study received some kind of intervention which could have interfered with the natural course of the condition. To avoid unnecessary interventions, in our center, we treat the patients only when there is an evidence-based indication. However, not to treat high-risk women when it is indicated would not be ethical, and this should be taken into account when evaluating the performance of a predictive tool in a treated population. The main strength is that this is the first study evaluating the predictive 
Table 3 Discriminative performance of the $\mathrm{CCl}$ and $\mathrm{CL}$ measured with ultrasound and the combination of the two measurements with regard to predicting spontaneous preterm birth $<34^{+0}$ weeks

\begin{tabular}{|c|c|c|c|c|c|c|c|}
\hline & Cutoff $^{\mathrm{a}}$ & $\begin{array}{l}\text { Sensitivity } \\
(95 \% \mathrm{Cl})\end{array}$ & $\begin{array}{l}\text { Specificity } \\
(95 \% \mathrm{Cl})\end{array}$ & $\begin{array}{l}\text { PPV } \\
(95 \% \mathrm{Cl})\end{array}$ & $\begin{array}{l}\text { NPV } \\
(95 \% \mathrm{Cl})\end{array}$ & $\begin{array}{l}\mathrm{LR}+ \\
(95 \% \mathrm{Cl})\end{array}$ & $\begin{array}{l}\text { LR- } \\
(95 \% \mathrm{Cl})\end{array}$ \\
\hline \multirow[t]{4}{*}{$\mathrm{CCl}$} & $<45 \%$ & $\begin{array}{l}21.4 \%(7.6-47.6) \\
(3 / 14)\end{array}$ & $\begin{array}{l}91.2 \%(82.1-95.9) \\
(62 / 68)\end{array}$ & $\begin{array}{l}33.3 \%(12.1-64.6) \\
(3 / 9)\end{array}$ & $\begin{array}{l}84.9 \%(75.0-91.4) \\
(62 / 73)\end{array}$ & $2.4(0.7-8.6)$ & $0.8(0.6-1.1)$ \\
\hline & $<50 \%$ & $\begin{array}{l}35.7 \%(16.3-61.2) \\
(5 / 14)\end{array}$ & $\begin{array}{l}80.9 \%(67.0-88.0) \\
(55 / 68)\end{array}$ & $\begin{array}{l}27.8 \%(12.5-50.9) \\
(5 / 18)\end{array}$ & $\begin{array}{l}85.9 \%(75.4-92.4) \\
(55 / 64)\end{array}$ & $1.9(0.8-4.4)$ & $0.8(0.5-1.2)$ \\
\hline & $<55 \%$ & $\begin{array}{l}50.0 \%(26.8-73.2) \\
(7 / 14)\end{array}$ & $\begin{array}{l}66.2 \%(54.3-76 .) \\
(45 / 68)\end{array}$ & $\begin{array}{l}23.3 \%(11.8-40.9) \\
(7 / 30)\end{array}$ & $\begin{array}{l}56.5 \%(74.7-93.3) \\
(45 / 52)\end{array}$ & $1.5(0.8-2.8)$ & $0.8(0.4-1.3)$ \\
\hline & $59.4 \%^{\mathrm{b}}$ & $\begin{array}{l}78.6 \%(52.4-92.4) \\
(11 / 14)\end{array}$ & $\begin{array}{l}58.8 \%(47.0-69.2) \\
(40 / 68)\end{array}$ & $\begin{array}{l}28.2 \%(16.5-43.8) \\
(11 / 39)\end{array}$ & $\begin{array}{l}93.0 \%(81.4-97.6) \\
(40 / 43)\end{array}$ & $1.9(1.3-2.8)$ & $0.4(01-1.0)$ \\
\hline \multirow[t]{3}{*}{$\mathrm{CL}$} & $\leq 20 \mathrm{~mm}$ & $\begin{array}{l}14.3 \%(4.0-39.9) \\
(2 / 14)\end{array}$ & $\begin{array}{l}88.2 \%(78.5-93.9) \\
(60 / 68)\end{array}$ & $\begin{array}{l}20.0 \%(5.7-51.0) \\
(2 / 10)\end{array}$ & $\begin{array}{l}83.3 \%(73.1-90.2) \\
(60 / 72)\end{array}$ & $1.2(0.3-5.1)$ & $0.9(0.8-1.2)$ \\
\hline & $<25 \mathrm{~mm}$ & $\begin{array}{l}28.6 \%(11.7-54.6) \\
(4 / 14)\end{array}$ & $\begin{array}{l}79.4 \%(68.4-87.3) \\
(54 / 68)\end{array}$ & $\begin{array}{l}22.2 \%(9.0-45.2) \\
(4 / 18)\end{array}$ & $\begin{array}{l}84.4 \%(73.6-91.3) \\
(54 / 64)\end{array}$ & $1.4(0.5-3.6)$ & $0.9(0.6-1.3)$ \\
\hline & $29.7 \mathrm{~mm}^{\mathrm{b}}$ & $\begin{array}{l}42.9 \%(21.4-67.4) \\
(6 / 14)\end{array}$ & $\begin{array}{l}69.1 \%(57.4-78.8) \\
(47 / 68)\end{array}$ & $\begin{array}{l}22.2 \%(10.6-40.8) \\
(6 / 27)\end{array}$ & $\begin{array}{l}85.5 \%(73.8-92.4) \\
(47 / 55)\end{array}$ & $1.4(0.7-2.8)$ & $0.8(0.5-1.3)$ \\
\hline $\begin{array}{l}\mathrm{CCl} \text { and } \mathrm{CL} \\
\text { below cutoff }\end{array}$ & $\begin{array}{l}<59.4 \% \text { and } \\
<29.7 \mathrm{~mm}\end{array}$ & $\begin{array}{l}40.9 \%(23.3-61.3) \\
(9 / 22)\end{array}$ & $\begin{array}{l}81.7 \%(70.1-89.4) \\
(49 / 60)\end{array}$ & $\begin{array}{l}45.0 \%(25.2-65.4) \\
(9 / 20)\end{array}$ & $\begin{array}{l}79.0 \%(67.4-87.3) \\
(49 / 62)\end{array}$ & $2.2(1.1-4.6)$ & $0.7(0.5-1.0)$ \\
\hline $\begin{array}{l}\mathrm{CCl} \text { or } \mathrm{CL} \\
\text { below cutoff }\end{array}$ & $\begin{array}{l}<59.4 \% \text { or } \\
<29.7 \mathrm{~mm}\end{array}$ & $\begin{array}{l}72.7 \%(51.8-86.8) \\
(16 / 22)\end{array}$ & $\begin{array}{l}53.3 \%(40.9-65.4) \\
(32 / 60)\end{array}$ & $\begin{array}{l}36.4 \%(23.8-51.1) \\
(16 / 44)\end{array}$ & $\begin{array}{l}84.2 \%(69.6-92.6) \\
(32 / 38)\end{array}$ & $1.6(1.1-2.3)$ & $0.5(0.2-1.1)$ \\
\hline
\end{tabular}

Abbreviations: $\mathrm{CCl}$, cervical consistency index; $\mathrm{Cl}$, confidence interval; $\mathrm{CL}$, cervical length; $\mathrm{LR}-$, negative likelihood ratio; $\mathrm{LR}+$, positive likelihood ratio; NPV, negative predictive value; PPV, positive predictive value.

${ }^{a}$ Values below the cutoff indicate increased risk.

boptimal cutoff based on the receiver operating characteristic curve.

capacity of CCI focused on high SPTB risk pregnancies between $19^{+0}$ and $24^{+6}$ weeks, at time at which treatment strategies are still useful. ${ }^{14-17}$ The main limitation of this study is the number of women included. This can be explained in that about half of women are referred to the PBPC after week $25^{+0}$ of pregnancy. Therefore, more efforts should be made to perform a complete risk assessment and refer women with risk factors as early as possible during gestation to maximize the usefulness and efficacy of the therapeutic strategies available. Offline measurements could also be considered a limitation of the study; however, we chose offline analysis to blind CCI measurements to caregivers and the women themselves. As mentioned earlier, we did not exclude women with pro-

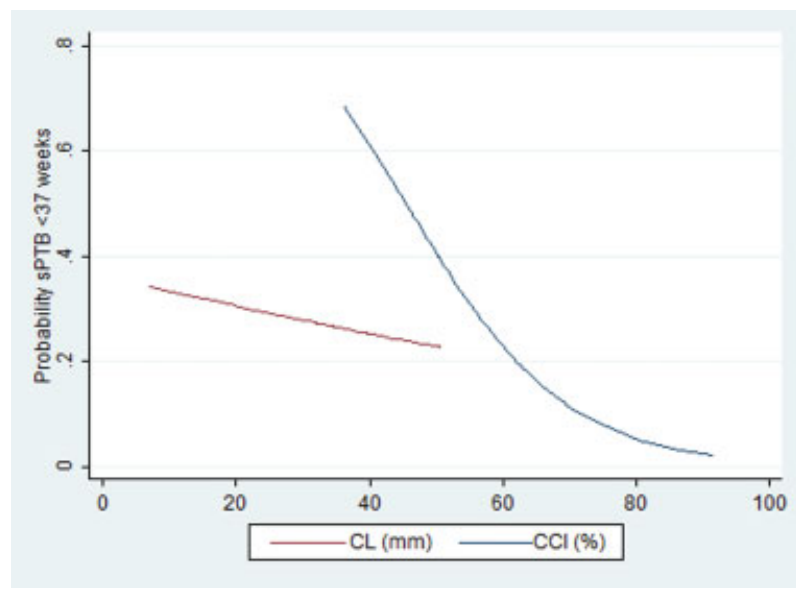

Fig. 4 Estimated probability of spontaneous preterm birth (sPTB) $<37$ weeks according to the cervical consistency index $(\mathrm{CCl})$ and cervical length $(\mathrm{CL})$ between 19 and 24 weeks of gestation. gesterone treatment or with a cervical cerclage, since treatment is indicated in a considerable number of high-risk patients $^{25}$ according to current guidelines ${ }^{26,27}$ and the protocol of our institution. Moreover, the main objective of the study was to compare the diagnostic accuracy between CCI and CL in the same high-risk cohort of women regardless of the treatment received. Based on the ROC curve (59.4\%), the optimal CCI cutoff in this high-risk population is close to the CCI cutoff of $60 \%$ suggested in a previous publication. ${ }^{24} \mathrm{~A} \mathrm{CCI}$ of $60 \%$, which corresponded to the 10 th centile in a low-risk population, had a sensitivity of $54.4 \%$ and a false positive rate of only $7.8 \%$, showing the best performance in a screening scenario. When applied to a high-risk population, in which we aim to optimize

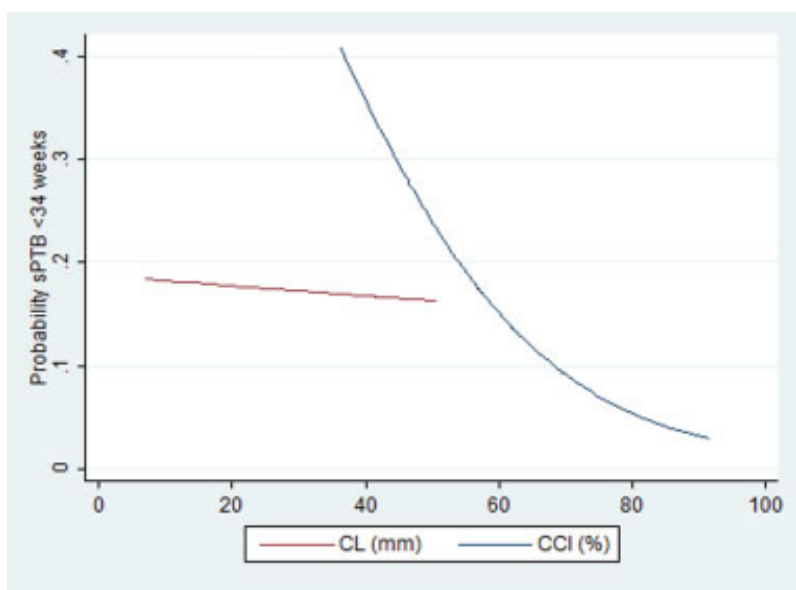

Fig. 5 Estimated probability of spontaneous preterm birth (sPTB) $<34$ weeks according to the cervical consistency index (CCI) and cervical length (CL) between 19 and 24 weeks of gestation. 
the sensitivity, the CCI cutoff of $60 \%$ has an improved sensitivity of $72.7 \%$ at the expense of increasing the false positive rate to $36.3 \%$, which might be acceptable in a high-risk population already receiving closer follow-up. It was of note that the CL cutoff of $25 \mathrm{~mm}$ used in clinical practice had a sensitivity of only $31.8 \%$ and a specificity of $81.7 \%$, and the optimal CL cutoff based on the ROC curve also showed poor performance. The technical limitations of the CCI (standardization of the acquisition, horizontal orientation of the cervical canal) are discussed in the previous CCI study ${ }^{24}$ and still need to be addressed. However, in a study performed under experimental conditions, when the maximum compressibility of the cervix was achieved, a variation in the force applied did not result in a significant variation in the strain, suggesting reproducibility and robustness among operators in the real clinical setting. ${ }^{28}$ Intra- and interobserver agreement and the reliability of the $\mathrm{CCI}$ demonstrated to be sufficient for clinical use in a previous study in a low-risk population. ${ }^{24}$ Regarding premature cervical remodeling, many efforts have been invested in studying the properties and composition of the cervix. ${ }^{18,29-36}$ Attempts have been made to evaluate cervical softening with various techniques. The aspiration method aims to assess the stiffness of ectocervical tissue. ${ }^{37}$ With this noninvasive tool, the pressure required to displace cervical tissue to a predefined deformation level can be determined. The aspiration technique confirmed that the tissue softens already at the beginning of pregnancy, progresses to a lower consistency in the first two trimesters, and stabilizes at a low level in the third trimester. ${ }^{30}$ However, the need for a specific device limits its application in clinical practice. Another method, the shear wave speed, allows objective characterization of stiffness because waves travel more slowly in softer tissue $^{38}$ and ultrasound imaging can be used to monitor the propagation of the shear wave and measure its speed. ${ }^{31} \mathrm{~A}$ cross-sectional study of women at 11 to 36 weeks of gestation found a positive correlation between softening and spontaneous preterm delivery although the results were not statistically significant. ${ }^{38}$ The results of both techniques confirm that cervical softening starts early in gestation until the second trimester and has a potential association with sPTB. Therefore, $\mathrm{CCI}$ aims to easily identify softer cervixes already from weeks $19^{+0}$ to $24^{+6}$ with a technically easy method. Promisingly, other tools aiming to identify premature decidual activation, such as fetal fibronectin alone $\mathrm{e}^{39-41}$ or in combination with $\mathrm{CL}^{42,43}$ are providing encouraging results in high-risk asymptomatic patients. Further studies with a larger number of high sPTB risk women are needed to confirm our results and to externally validate $\mathrm{CCI}$ measurement. A larger sample size would also allow stratification by risk factors, minimizing the phenotypic heterogeneity within the sample, and thereby allowing more accurate conclusions about the predictive capacity of the $\mathrm{CCI}$ in specific populations. Moreover, the discriminative capacity of the $\mathrm{CCI}$ when calculated during the examination should be compared with that of the offline analysis. According to a new paradigm, the three mechanisms which trigger sPTB (premature decidual activation, premature myometrial activation, and premature cervical remodeling) are inextricably intertwined with each other ${ }^{44}$ reinforcing the suitability of exploring the combination of cervical assessment with tests assessing other mechanisms. Finally, the limited predictive capacity of both the $\mathrm{CL}$ and $\mathrm{CCI}$ to evaluate the cervix, particularly in the high-risk population, also supports the need to continue developing other ultrasound tools to improve the identification of women at increased risk of SPTB among those with known risk factors.

\section{Conflict of Interest}

The authors declare no conflict of interest.

\section{Presentation}

This study was presented at "The 2017 37th Annual Pregnancy Meeting," Society of Maternal-Fetal Medicine, Las Vegas, NV, January 26, 2017.

Control ID 1517, Program ID 309, Poster session II.

\section{Acknowledgments}

This study was funded with the support of the Erasmus + Program of the European Union (Framework Agreement number: 2013-0040) (This publication only reflects the views of the author, and the Commission cannot be held responsible for any use which may be made of the information contained therein). In addition, the research leading to these results has partially received funding from "la Caixa" Foundation; Cerebra Foundation for the Brain Injured Child (Carmarthen, Wales, UK); AGAUR 2014 SGR grant number 928 and "la Secretaria d'Universitats i Recerca del Departament d'Economia i Coneixement de la Generalitat de Catalunya (A.P: 2014DI083)."

\section{References}

1 Goldenberg RL, Culhane JF, Iams JD, Romero R. Epidemiology and causes of preterm birth. Lancet 2008;371(9606):75-84

2 Iams JD, Berghella V. Care for women with prior preterm birth. Am J Obstet Gynecol 2010;203(02):89-100

3 Reichman D, Laufer MR, Robinson BK. Pregnancy outcomes in unicornuate uteri: a review. Fertil Steril 2009;91(05):1886-1894

4 Crane J, Scott H, Stewart A, Chandra S, Whittle W, Hutchens D. Transvaginal ultrasonography to predict preterm birth in women with bicornuate or didelphus uterus. J Matern Fetal Neonatal Med 2012;25(10):1960-1964

5 Bruinsma F, Lumley J, Tan J, Quinn M. Precancerous changes in the cervix and risk of subsequent preterm birth. BJOG 2007;114(01): 70-80

6 Celik E, To M, Gajewska K, Smith GC, Nicolaides KH; Fetal Medicine Foundation Second Trimester Screening Group. Cervical length and obstetric history predict spontaneous preterm birth: development and validation of a model to provide individualized risk assessment. Ultrasound Obstet Gynecol 2008;31(05):549-554

7 Care AG, Sharp AN, Lane S, Roberts D, Watkins L, Alfirevic Z. Predicting preterm birth in women with previous preterm birth and cervical length $\geq 25$ mm. Ultrasound Obstet Gynecol 2014;43(06):681-686

8 Reilly R, Paranjothy S, Beer H, Brooks CJ, Fielder HM, Lyons RA. Birth outcomes following treatment for precancerous changes to the cervix: a population-based record linkage study. BJOG 2012; 119(02):236-244

9 Airoldi J, Berghella V, Sehdev H, Ludmir J. Transvaginal ultrasonography of the cervix to predict preterm birth in women with uterine anomalies. Obstet Gynecol 2005;106(03):553-556 
10 Hughes K, Kane SC, Araujo Júnior E, Da Silva Costa F, Sheehan PM. Cervical length as a predictor for spontaneous preterm birth in high-risk singleton pregnancy: current knowledge. Ultrasound Obstet Gynecol 2016;48(01):7-15

11 Berghella V, Pereira L, Gariepy A, Simonazzi G. Prior cone biopsy: prediction of preterm birth by cervical ultrasound. Am J Obstet Gynecol 2004;191(04):1393-1397

12 Miller ES, Grobman WA. The association between cervical excisional procedures, midtrimester cervical length, and preterm birth. Am J Obstet Gynecol 2014;211(03):242.e1-242.e4

13 Poon LC, Savvas M, Zamblera D, Skyfta E, Nicolaides KH. Large loop excision of transformation zone and cervical length in the prediction of spontaneous preterm delivery. BJOG 2012;119(06):692-698

14 Romero R, Nicolaides KH, Conde-Agudelo A, et al. Vaginal progesterone decreases preterm birth $\leq 34$ weeks of gestation in women with a singleton pregnancy and a short cervix: an updated meta-analysis including data from the OPPTIMUM study. Ultrasound Obstet Gynecol 2016;48(03):308-317

15 Goya M, Pratcorona L, Merced C, et al; Pesario Cervical para Evitar Prematuridad (PECEP) Trial Group. Cervical pessary in pregnant women with a short cervix (PECEP): an open-label randomised controlled trial. Lancet 2012;379(9828):1800-1806

16 Nicolaides KH, Syngelaki A, Poon LC, et al. A randomized trial of a cervical pessary to prevent preterm singleton birth. N Engl J Med 2016;374(11):1044-1052

17 Berghella V, Rafael TJ, Szychowski JM, Rust OA, Owen J. Cerclage for short cervix on ultrasonography in women with singleton gestations and previous preterm birth: a meta-analysis. Obstet Gynecol 2011;117(03):663-671

18 Parra-Saavedra M, Gómez L, Barrero A, Parra G, Vergara F, Navarro E. Prediction of preterm birth using the cervical consistency index. Ultrasound Obstet Gynecol 2011;38(01):44-51

19 Word RA, Li XH, Hnat M, Carrick K. Dynamics of cervical remodeling during pregnancy and parturition: mechanisms and current concepts. Semin Reprod Med 2007;25(01):69-79

20 Timmons B, Akins M, Mahendroo M. Cervical remodeling during pregnancy and parturition. Trends Endocrinol Metab 2010;21 (06):353-361

21 Feltovich H, Hall TJ, Berghella V. Beyond cervical length: emerging technologies for assessing the pregnant cervix. Am J Obstet Gynecol 2012;207(05):345-354

22 Read CP, Word RA, Ruscheinsky MA, Timmons BC, Mahendroo MS. Cervical remodeling during pregnancy and parturition: molecular characterization of the softening phase in mice. Reproduction 2007;134(02):327-340

23 Westervelt AR, Fernandez M, House M, et al. A parameterized ultrasound-based finite element analysis of the mechanical environment of pregnancy. J Biomech Eng 2017;139(05). doi: $10.1115 / 1.4036259$

24 Baños N, Murillo-Bravo C, Julià C, et al. Mid-trimester sonographic cervical consistency index to predict spontaneous preterm birth in a low-risk population. Ultrasound Obstet Gynecol 2017 doi: 10.1002/uog.17482

25 Crane JM, Hutchens D. Transvaginal sonographic measurement of cervical length to predict preterm birth in asymptomatic women at increased risk: a systematic review. Ultrasound Obstet Gynecol 2008;31(05):579-587

26 Iams JD. Clinical practice. Prevention of preterm parturition. N Engl J Med 2014;370(03):254-261

27 Alfirevic Z, Owen J, Carreras Moratonas E, Sharp AN, Szychowski JM, Goya M. Vaginal progesterone, cerclage or cervical pessary for preventing preterm birth in asymptomatic singleton pregnant women with a history of preterm birth and a sonographic short cervix. Ultrasound Obstet Gynecol 2013;41(02):146-151
28 Maurer MM, Badir S, Pensalfini M, et al. Challenging the in-vivo assessment of biomechanical properties of the uterine cervix: a critical analysis of ultrasound based quasi-static procedures. J Biomech 2015;48(09):1541-1548

29 Hee L, Liao D, Sandager P, Gregersen H, Uldbjerg N. Cervical stiffness evaluated in vivo by endoflip in pregnant women. PLoS One 2014;9 (03):e91121

30 Badir S, Mazza E, Zimmermann R, Bajka M. Cervical softening occurs early in pregnancy: characterization of cervical stiffness in 100 healthy women using the aspiration technique. Prenat Diagn 2013;33(08):737-741

31 Fruscalzo A, Mazza E, Feltovich H, Schmitz R. Cervical elastography during pregnancy: a critical review of current approaches with a focus on controversies and limitations. J Med Ultrason (2001) 2016;43(04):493-504

32 Banos N, Perez-Moreno A, Migliorelli F, et al. Quantitative analysis of the cervical texture by ultrasound and correlation with gestational age. Fetal Diagn Ther 2017;41(04):265-272

33 Carlson LC, Feltovich H, Palmeri ML, Dahl JJ, Munoz del Rio A, Hall TJ. Estimation of shear wave speed in the human uterine cervix. Ultrasound Obstet Gynecol 2014;43(04):452-458

34 Peralta L, Mourier E, Richard C, et al. In vivo evaluation of cervical stiffness evolution during induced ripening using shear wave elastography, histology and 2 photon excitation microscopy: insight from an animal model. PLoS One 2015;10(08):e0133377

35 Fittkow CT, Maul H, Olson G, et al. Light-induced fluorescence of the human cervix decreases after prostaglandin application for induction of labor at term. Eur J Obstet Gynecol Reprod Biol 2005; 123(01):62-66

36 McFarlin BL, Bigelow TA, Laybed Y, O’Brien WD, Oelze ML, Abramowicz JS. Ultrasonic attenuation estimation of the pregnant cervix: a preliminary report. Ultrasound Obstet Gynecol 2010;36(02):218-225

37 Badir S, Bajka M, Mazza E. A novel procedure for the mechanical characterization of the uterine cervix during pregnancy. J Mech Behav Biomed Mater 2013;27:143-153

38 Hernandez-Andrade E, Aurioles-Garibay A, Garcia M, et al. Effect of depth on shear-wave elastography estimated in the internal and external cervical os during pregnancy. J Perinat Med 2014;42 (05):549-557

39 Abbott DS, Hezelgrave NL, Seed PT, et al. Quantitative fetal fibronectin to predict preterm birth in asymptomatic women at high risk. Obstet Gynecol 2015;125(05):1168-1176

40 Kurtzman J, Chandiramani M, Briley A, Poston L, Das A, Shennan A. Quantitative fetal fibronectin screening in asymptomatic high-risk patients and the spectrum of risk for recurrent preterm delivery. Am J Obstet Gynecol 2009;200(03):263. e1-263.e6

41 Hezelgrave NL, Abbott DS, Radford SK, et al. Quantitative fetal fibronectin at 18 weeks of gestation to predict preterm birth in asymptomatic high-risk women. Obstet Gynecol 2016;127(02): 255-263

42 Kuhrt K, Smout E, Hezelgrave N, Seed PT, Carter J, Shennan AH Development and validation of a tool incorporating cervical length and quantitative fetal fibronectin to predict spontaneous preterm birth in asymptomatic high-risk women. Ultrasound Obstet Gynecol 2016;47(01):104-109

43 Bolt LA, Chandiramani M, De Greeff A, Seed PT, Kurtzman J, Shennan AH. The value of combined cervical length measurement and fetal fibronectin testing to predict spontaneous preterm birth in asymptomatic high-risk women. J Matern Fetal Neonatal Med 2011;24(07):928-932

44 Vink J, Feltovich H. Cervical etiology of spontaneous preterm birth. Semin Fetal Neonatal Med 2016;21(02):106-112 